\title{
Salt Effect on the Cloud Point Phenomenon of Amphiphilic Drug-Hydroxypropylmethyl Cellulose System
}

\author{
Mohd. Sajid Ali, ${ }^{1}$ Dileep Kumar, ${ }^{2}$ and Hamad A. Al-Lohedan' \\ ${ }^{1}$ Surfactant Research Chair, Department of Chemistry, College of Science, King Saud University, Riyadh 11541, Saudi Arabia \\ ${ }^{2}$ Department of Chemistry, Aligarh Muslim University, Aligarh 202002, India \\ Correspondence should be addressed to Mohd. Sajid Ali; smsajidali@gmail.com
}

Received 12 January 2014; Revised 20 March 2014; Accepted 20 March 2014; Published 13 April 2014

Academic Editor: Jean-Luc Blin

Copyright (c) 2014 Mohd. Sajid Ali et al. This is an open access article distributed under the Creative Commons Attribution License, which permits unrestricted use, distribution, and reproduction in any medium, provided the original work is properly cited.

\begin{abstract}
Effect of two amphiphilic drugs (tricyclic antidepressant, nortriptyline hydrochloride (NORT), and nonsteroidal anti-inflammatory drug, sodium salt of ibuprofen (IBF)) on the cloud point of biopolymer hydroxypropylmethyl cellulose (HPMC) was studied. Effect of $\mathrm{NaCl}$ was also seen on the CP of HPMC-drug system. CP of HPMC increases uniformly on increasing the (drug). Both drugs, though one being anionic (IBF) and other cationic (NORT), affect the CP in almost the same manner but with different extent implying the role of hydrophobicity in the interaction between drug and polymer. Salt affects the CP of the drug in a dramatic way as low concentration of salt was only able to increase the value of the $\mathrm{CP}$, though not affecting the pattern. However, in presence of high concentration of salts, minimum was observed on CP versus (drug) plots. Various thermodynamic parameters were evaluated and discussed on the basis of the observed results.
\end{abstract}

\section{Introduction}

Owing to their nontoxic nature, derivatives of a number of biopolymers (cellulose, starch, etc.) play important roles in food, pharmaceutical, and cosmetics industries where careful addition can be used to regulate the rheology of the system [1]. Hydroxypropylmethyl cellulose (HPMC), a nonionic cellulose ether, is such an important amphiphilic carrier material used for the preparation of controlled drug delivery systems [2]. Due to its prominent viscoelastic and structure forming properties, it is employed as a flow developer, as a tablet binder, as a tablet disintegrant, as a wet granulation binder, and also as an suspending and thickening agent $[3,4]$. When heated up to a certain temperature (known as cloud point, CP, or lower critical solution temperature, LCST), aqueous solutions of some polymers have a tendency for reversible phase separation [5-11]. The LCST implies that the effective solute-solute interactions have a noteworthy temperature dependences and alterations from repulsive to attractive with increasing temperature. The $\mathrm{CP}$ phenomenon of cellulose ethers is believed to be due to the decrease in the dipolar character of the $\mathrm{C}-\mathrm{O}$ bond as a result of either increase in temperature or making the solvating environment less polar [5-11]. The cloud point of HPMC is affected by the presence of amphiphiles as well as electrolytes, but both of them influence it differently $[10,11]$. Clouding of polymers is strongly dependent on the cosolutes. Electrolytes may either increase or decrease the cloud point and may be termed salting in or salting out, respectively, which is generally dependent on the Hofmeister series [9]. Surfactants play significant role in polymer chemistry due to their amphiphilic nature $[12,13]$. The hydrophobic interaction together with hydrophilic or polar interaction (electrostatic interaction in case of polymers and surfactants of opposite charges) confers the polymer-surfactant complex fairly new properties [12$14]$.

The drugs of several types, such as tricyclic antidepressants, phenothiazines, nonsteroidal anti-inflammatory drugs, exhibit amphiphilic character and are capable of producing ordinary micelles or micelle-like aggregates at or above a concentration [15-20] known as critical micelle concentration.

Drug delivery formulations are designed in such a way that these are either targeted, sustained, or stimuli responsive [21-23]. Sometimes it is desired to target the therapeutic agents according to the physiological conditions of the particular organ. Since electrolytes have a tremendous role in 
the biological processes, we have designed our study which is based on the phase separation of the polymer affected by amphiphilic drugs in presence of $\mathrm{NaCl}$, which is often used as excipient in various drug formulations [24-26]. The results may be helpful to modulate the delivery systems which contain the cellulose derivatives. The targeted as well as sustained release can be achieved by taking desired amount of drug in combination with the appropriate quantity of the electrolyte.

In this study effect of two amphiphilic drugs, nortriptyline hydrochloride (NORT) and sodium salt of ibuprofen (IBF), on the phase separation of cellulose ether HPMC was seen in pure aqueous medium and in presence of $\mathrm{NaCl}$.

\section{Experimental Section}

hydroxypropylmethyl cellulose, HPMC (molecular weight 10,000 , hydroxypropoxyl content $\sim 9 \%$, 99\%, Fluka, Japan), nortriptyline hydrochloride, NORT (99.0\%, Sigma, USA), sodium salt of ibuprofen, IBF ( $>99 \%$, Sigma, USA), were used as received.

Freshly prepared stock solutions of the polymer were used to obtain samples for CP measurements (containing HPMC with or without drugs). CPs were obtained by placing Pyrex glass tubes (containing the sample solutions) into a temperature controlled bath, the temperature of which was ramped at the rate of $0.1^{\circ} \mathrm{C} / \mathrm{min}$ near the $\mathrm{CP}$, and onset of clouding was noted by visual inspection. However, the temperature was oscillated slowly through the $\mathrm{CP}$ until reproducible $\left( \pm 0.1^{\circ} \mathrm{C}\right)[10,11]$. Critical micelle concentration of the drug was determined by conductivity measurement and the experimental details are given elsewhere [20].

\section{Results and Discussion}

3.1. Effect of Amphiphilic Drugs on Cloud Point of HPMC. Structures of both IBF and NORT are given in Scheme 1. IBF is a well-known nonsteroidal anti-inflammatory drug which is surface active and found to behave like hydrotropes [27] with an anionic head group, whereas NORT, which belongs to tricyclic antidepressant category, is also an amphiphilic cationic drug [14]. When the solution of pure HPMC $(1 \% \mathrm{w} / \mathrm{v})$ is heated, phase separation occurs at about $60^{\circ} \mathrm{C}$; this means that below this temperature HPMC molecules are surrounded by a network of water molecules and, at higher temperature, entropy destroys the network and phase separation occurs due to the weak van der Waals' attraction between the polymer chains [28].

Figure 1 describes the effect of IBF and NORT on the cloud point of HPMC $(1 \% \mathrm{w} / \mathrm{v})$. Effect of both drugs is similar; that is, on increasing the drugs concentration $\mathrm{CP}$ increases (Figure 1). When mixed together, both polymers and amphiphiles are known to increase the solubility of each other. It can be discussed in terms of the change in the hydrophobic/hydrophilic balance in the system and, as a result, modification of the interaction [29]. Since the interaction of HPMC with IBF and NORT starts with the binding of drug and polymer the resulting complex could be<smiles>CC(C)Cc1ccc(C(C)C(=O)O[Na])cc1</smiles>

Sodium salt of ibuprofen

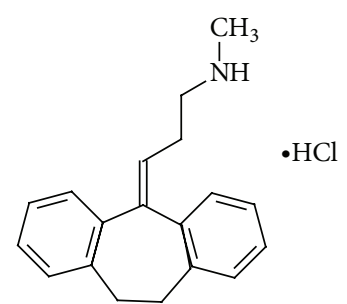

Nortriptyline hydrochloride
SCHEME 1

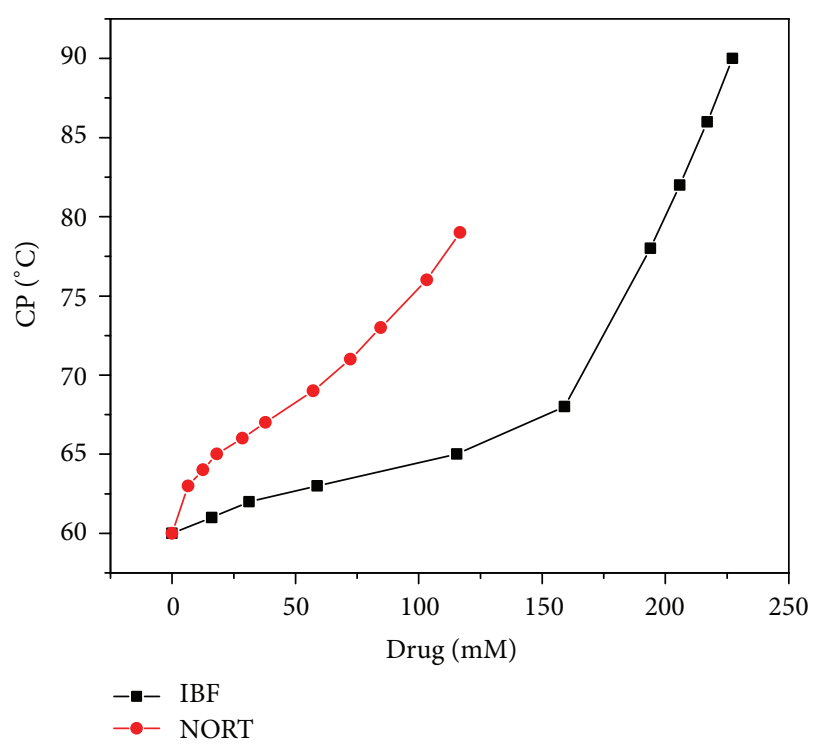

Figure 1: Effect of amphiphilic drugs on the CP of HPMC.

considered as a polyelectrolyte. It is evident from Figure 1 that addition of small amount of drugs causes the CP to increase due to the beginning of the increased interaction between HPMC and drug. This indicates a high degree binding between polymer and drug. The $\mathrm{CP}$ change of the polymer on addition of amphiphile is governed by a delicate balance between electrostatic, hydrophobic and steric interactions. When more amounts of drug are added, the increase in the effective charge density (due to the drug-polymer binding) may lead to increase in the repulsive electrostatic forces. Amphiphiles play an important role in polymer chemistry due to their unique amphiphilic feature $[12,13]$. For example, hydrophobic portion of amphiphile interacts with hydrophobic polymers or rather with hydrophobic groups of water soluble polymers and the formed complex has somewhat new properties due to the presence of hydrophilic portion of amphiphile. The other factor which is also significant is the steric hindrance between the bulky groups of the polymer chain and amphiphile. Steric repulsion is the unfavorable interaction between drug and polymer segments [30]. The distinct increase of CP with higher concentration of amphiphile is a usual sign of polymer's strong binding with amphiphile. Since IBF is less hydrophobic as compared to NORT which is clearly understood by their respective 


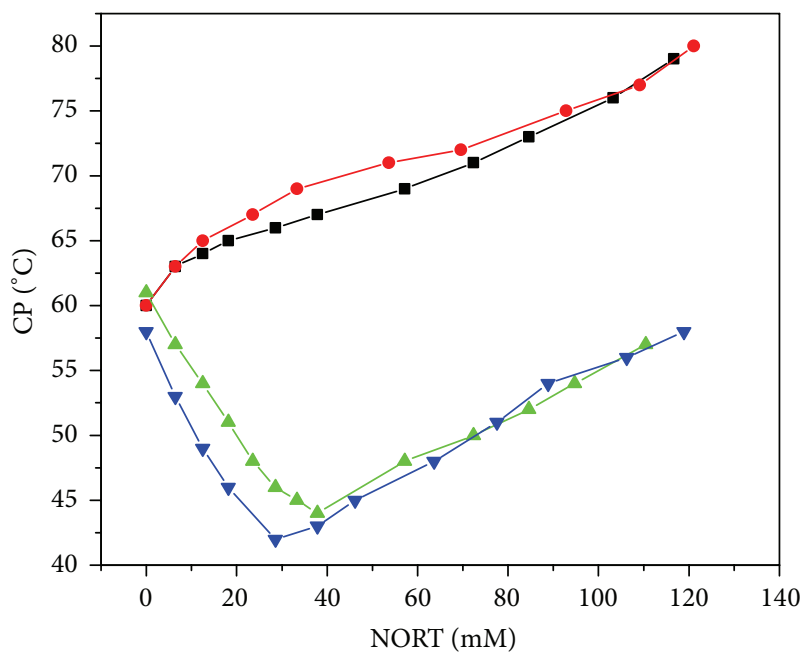

$\mathrm{NaCl}(\mathrm{mM})$

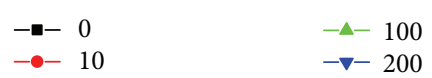

FIGURE 2: Effect of various concentrations of $\mathrm{NaCl}$ on the $\mathrm{CP}$ of the NORT-HPMC system.

CMCs (NORT; $23 \mathrm{mM}$ [20] and IBF; $90 \mathrm{mM}$ [27]), the latter is more effective in increasing the CP of HPMC (Figure 1) due to stronger interaction with the hydrophobic portions of HPMC. Though, on the basis of their chemical structure (Scheme 1), steric hindrance will be more in case of NORT as compared to IBF, it seems that its effect is negligible as compared to the hydrophobic as well as electrostatic interaction. In case of IBF, significant change in the CP is observed when the drug reaches around $150 \mathrm{mM}$ and this can be explained on the basis of the critical micelle concentration (CMC) of the drug in presence of polymer [20]. Since at CMC the solubility changes dramatically, it can be concluded that the polymer was solubilized by the micelles of drug and it causes the increase of the solubility which eventually affects the CP. Though NORT has also followed a similar pattern, in this case such a break is not so prominent (Figure 1) and if we carefully examine, it seems to appear at around $40 \mathrm{mM}$. For confirming this break point we have examined the CMC of the NORT in presence of $1 \% \mathrm{w} / \mathrm{v}$ HPMC and it was found to be $38 \mathrm{mM}$ (Figure $\mathrm{S} 1$ ).

The presence of electrolytes has long been known to alter the physicochemical properties of both amphiphiles and polymers [31-33]. Micelle formation of amphiphiles shifts to the lower concentrations when salts are present $[31,32]$. Salts also influence the polymer-solvent interactions and thus the CP. Salts, when added, usually prefer an aqueous environment and remain away from the polymer. Consequently, the polarity of the solvent increased resulting in the lowering of the chemical potential of water and an increase of the surface tension between polymer and water. This leads to the increase in hydrophobicity, decrease in the solubility of the polymer, and a subsequent decrease in the CP [34]. NaCl, when present in low amount (Figures 2 and 3), did not influence the polarity of water and hydrophobicity of the polymer-drug
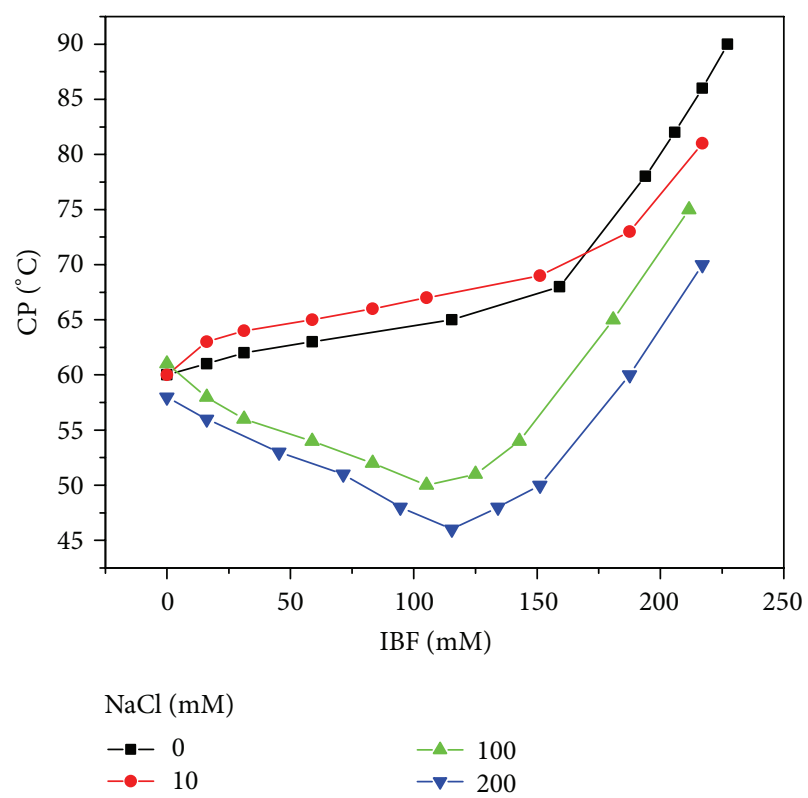

FIGURE 3: Effect of various concentrations of $\mathrm{NaCl}$ on the $\mathrm{CP}$ of the IBF-HPMC system.

complex significantly; that is why the system behaved like salt-free solution. However, when the salinity increased, the CP pattern initially followed the typical pattern and there was a notable decrease in the $\mathrm{CP}$ in presence of $100 \mathrm{mM} \mathrm{NaCl}$ which becomes more prominent on further increase in salt concentration. For the drug-polymer complex, it can be concluded that, in presence of high concentration of salts, the initial decrease of $\mathrm{CP}$ is due to the shielding of the ionic head groups of the drug molecules adsorbed to the HPMC [29]. In presence of salt, screening of repulsive forces occurs and due to the presence of hydrophobic portions the attractive forces start to dominate. Due to salting out from the water phase (repulsive ion-hydrocarbon interactions), increase in the interior hydrophobicity of both drug and polymer occurs which increased the drug-polymer binding. Since the resulting complex could be considered as polyelectrolyte, it remained away from the water phase due to salting out of the hydrophobic phase. This overall phenomenon leads to the lowering in CP on increase in the salinity. At high concentration of drug, likely formation of the micelles may lead to the increase in the CP since the influence of the intermicellar repulsion, along with a preference for the polar part of the polymer chain by the micelles, may become important. The preference of hydrophobic portion of the polymer to the hydrophobic core of the micelles in aqueous medium also favors the increased solubility of the polymerdrug complex and the decrease in the hydrophobic repulsion of the solvent and polymer-drug complex [29, 35].

3.2. Thermodynamics of the Cloud Point. It is clear that CP is regarded as the formation of the separate phases of the components present in the solution. Several studies report the explanation of the clouding phenomenon in terms of the energetics which is based on the solubility of the clouding 


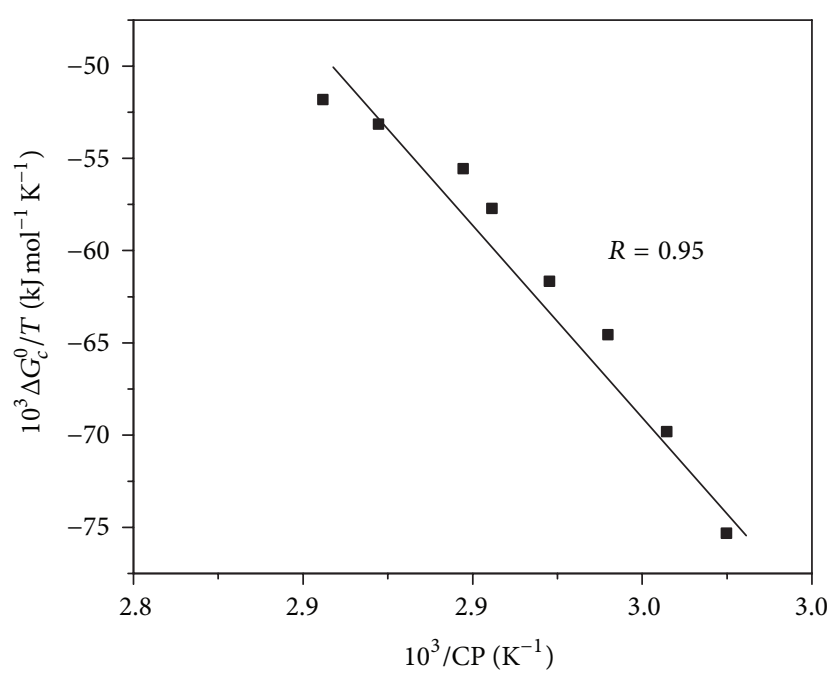

FIgUre 4: $\Delta G_{c}^{0} / T$ versus $1 / T$ plot of the NORT-HPMC system in presence of $10 \mathrm{mM} \mathrm{NaCl}$ (type 1 ).

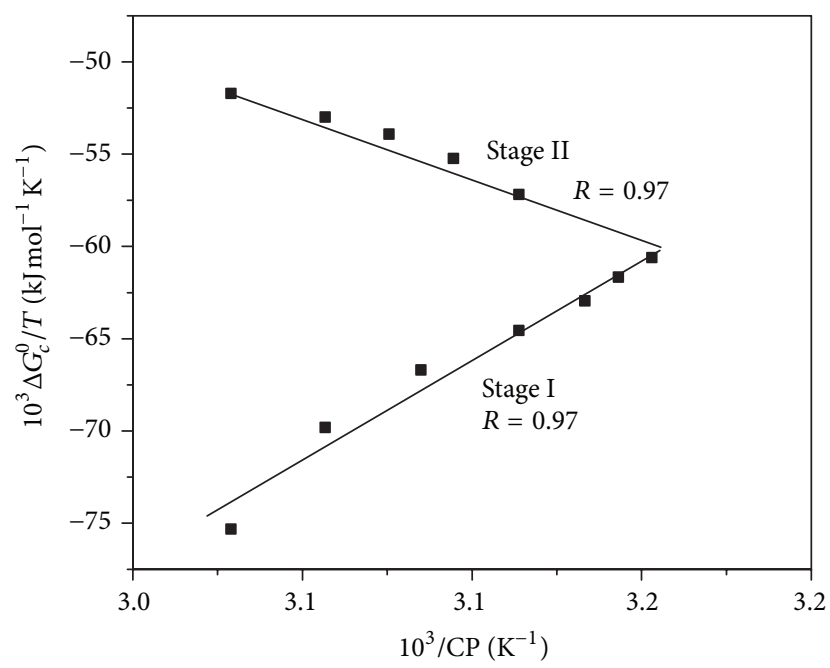

FIGURE 5: $\Delta G_{c}^{0} / T$ versus $1 / T$ plot of the NORT-HPMC system in presence of $100 \mathrm{mM} \mathrm{NaCl}$ (type 2).

species (in terms of mole fractions) in presence of various additives [36,37]. The water is separated from the clouding components and set aside from the solution. Therefore, CP can also be regarded as the solubility constraints of the clouding components at that temperature. The free energy of phase separation or clouding $\left(\Delta G_{c}^{0}\right)$ is as follows:

$$
\Delta G_{c}^{0}=R T \ln X,
$$

where $X, R$, and $T$ are mole fractional solubility at $\mathrm{CP}$, the gas constant $\left(8.314 \mathrm{JK}^{-1} \mathrm{~mol}^{-1}\right)$, and absolute temperature (CP + $273.15 \mathrm{~K})$, respectively.

$\Delta H_{c}^{0}$ can then be obtained from the slope of the linear (least square) plot between $\left(\Delta G_{c}^{0} / T\right)$ shown in Figures 4 and 5 as follows:

$$
\frac{\delta\left(\Delta G_{c}^{0} / T\right)}{\delta(1 / T)}=\Delta H_{c}^{0}
$$

and the entropy changes by using the Gibbs-Helmholtz equation:

$$
\Delta S_{c}^{0}=\frac{\left(\Delta H_{c}^{0}-\Delta G_{c}^{0}\right)}{T} .
$$

Table 1 enlists the values of thermodynamic parameters at the cloud point with respect to HPMC concentration. On the basis of our observations we have divided our results into two categories, that is, type 1 and type 2. Since CP of HPMCdrug system increases on increasing the drug in absence and presence of $10 \mathrm{mM} \mathrm{NaCl}$, these systems fall under type 1 system. Systems containing higher amounts of salts have been placed under type 2 systems.

The CP of HPMC for both systems (type 1 and type 2) decreases on increasing its concentration at fixed drug concentration $(50 \mathrm{mM})$ and $\Delta G_{c}^{0}$ becomes less negative (indicating that the clouding is becoming energetically less favorable on increasing the concentration of the polymer). 
TABLE 1: Cloud point (CP) and energetic parameters for clouding in different weight percent of HPMC solutions in the presence of NORT $(50 \mathrm{mM})$ and IBF $(50 \mathrm{mM})$ in presence and absence of various salts. The uncertainties in the CP values lie within \pm 0.1 degree.

\begin{tabular}{|c|c|c|c|c|c|c|c|c|c|}
\hline $\begin{array}{l}\text { HPMC } \\
\% \mathrm{w} / \mathrm{v}\end{array}$ & $\begin{array}{c}\mathrm{CP} \\
\mathrm{K}\end{array}$ & $\begin{array}{l}\Delta G_{c}{ }^{0} \\
\mathrm{~kJ} / \mathrm{mol} \\
\text { NORT }\end{array}$ & $\begin{array}{c}\Delta H_{c}{ }^{0} \\
\mathrm{~kJ} / \mathrm{mol}\end{array}$ & $\begin{array}{l}T \Delta S_{c}{ }^{0} \\
\mathrm{~kJ} / \mathrm{mol}\end{array}$ & $\begin{array}{c}\text { HPMC } \\
\% \mathrm{w} / \mathrm{v}\end{array}$ & $\begin{array}{c}\mathrm{CP} \\
\mathrm{K}\end{array}$ & $\begin{array}{c}\Delta G_{c}{ }^{0} \\
\mathrm{~kJ} / \mathrm{mol} \\
\mathrm{IBF}\end{array}$ & $\begin{array}{c}\Delta H_{c}^{0} \\
\mathrm{~kJ} / \mathrm{mol}\end{array}$ & $\begin{array}{l}T \Delta S_{c}{ }^{0} \\
\mathrm{~kJ} / \mathrm{mol}\end{array}$ \\
\hline \multicolumn{10}{|c|}{ Pure water } \\
\hline 0.10 & 353.15 & -50.63 & 186.02 & 236.65 & 0.10 & 353.15 & -50.63 & 133.38 & 184.01 \\
\hline 0.20 & 351.15 & -48.32 & & 234.34 & 0.20 & 349.15 & -48.04 & & 181.42 \\
\hline 0.50 & 347.15 & -45.12 & & 231.15 & 0.50 & 343.15 & -44.60 & & 177.98 \\
\hline 1.00 & 341.15 & -42.38 & & 228.40 & 1.00 & 336.15 & -41.75 & & 175.14 \\
\hline \multicolumn{10}{|c|}{$10 \mathrm{mM} \mathrm{NaCl}$} \\
\hline 0.10 & 359.15 & -51.49 & 154.12 & 205.61 & 0.10 & 354.15 & -50.77 & 146.34 & 197.11 \\
\hline 0.20 & 356.15 & -49.01 & & 203.13 & 0.20 & 349.15 & -48.04 & & 194.38 \\
\hline 0.50 & 352.15 & -45.77 & & 199.89 & 0.50 & 344.15 & -44.73 & & 191.08 \\
\hline 1.00 & 344.15 & -42.75 & & 196.87 & 1.00 & 338.15 & -42.01 & & 188.35 \\
\hline \multicolumn{10}{|c|}{$100 \mathrm{mM} \mathrm{NaCl}$} \\
\hline 0.10 & 343.15 & -49.20 & 85.16 & 134.36 & 0.10 & 342.15 & -49.05 & 147.02 & 196.07 \\
\hline 0.20 & 338.15 & -46.53 & & 131.69 & 0.20 & 337.15 & -46.39 & & 193.41 \\
\hline 0.50 & 332.15 & -43.18 & & 128.34 & 0.50 & 333.15 & -43.30 & & 190.32 \\
\hline 1.00 & 319.15 & -39.65 & & 124.81 & 1.00 & 327.15 & -40.63 & & 187.65 \\
\hline \multicolumn{10}{|c|}{$200 \mathrm{mM} \mathrm{NaCl}$} \\
\hline 0.10 & 341.15 & -48.91 & 93.86 & 142.77 & 0.10 & 341.15 & -48.91 & 144.74 & 193.64 \\
\hline 0.20 & 336.15 & -46.26 & & 140.11 & 0.20 & 336.15 & -46.25 & & 190.99 \\
\hline 0.50 & 330.15 & -42.92 & & 136.77 & 0.50 & 331.15 & -43.04 & & 187.78 \\
\hline 1.00 & 319.15 & -39.65 & & 133.50 & 1.00 & 326.15 & -40.51 & & 185.25 \\
\hline
\end{tabular}

The system becomes slightly more ordered on increasing the polymer as indicated by a decrease in the entropy of all the systems used in the study.

While seeing the effect of polymer concentration on the energetics of clouding, it was found that $\Delta H_{c}^{0}$ was almost of comparable magnitudes for a particular type and type 2 systems were more endothermic as compared to type 1 .

The values of energetic parameters for both drugs at varying drug and 1\% w/v HPMC are given in Table 2. For type 1 systems the $\Delta G_{c}^{0}$ becomes less negative on increasing the drug concentration. In case of type 2 systems $\Delta G_{c}^{0} / T$ versus $1 / T$ curves have two stages (Figures $2-5$ ). The first stage belongs to the lower concentrations of drug and is entropy controlled with positive entropy and enthalpy, while the second stage is mainly controlled by enthalpy; that is, the process is exothermic and the system becomes more ordered in this stage. It is concluded that type 1 systems are controlled by enthalpy with a significant ordering of the system. A large amount of heat is liberated during the complex formation between the HPMC and the amphiphilic drugs.

Stage I. It is apparent from Table 2 that entropy of the system for type 1 systems is positive for the endothermic process. As mentioned above that $\mathrm{CP}$ occurs due to the increased entropy of the system, drug monomers, when added to the system, further increase the overall entropy due to their interaction with the polymer making the system more disordered by affecting the water structure. Therefore, it can be concluded that the system becomes more disordered and the absorption of heat also takes place during stage I.

Stage II. The second stage is enthalpy controlled with negative entropy. This occurs probably due to the formation of ordered complexes which are generally formed at higher concentrations of drugs. The formation of complexes at higher concentration ends up with the release of heat with overall ordering of the system.

\section{Conclusions}

Effect of $\mathrm{NaCl}$ was seen on the cloud point (CP) of the nonionic polymer hydroxypropylmethyl cellulose (HPMC) and amphiphlic drug system. In absence and in presence of low salt the CP of HPMC was found to be increased on increasing the drug concentrations. However, in presence of high concentrations of salt, amphiphilic drugs were found to influence the CP in a manner that, on increasing the drug concentration, CP first decreased and then started increasing after reaching a minimum. It was concluded that the main driving force of the interaction between the amphiphilic 
TABLE 2: Effect of drug on the cloud point (CP) and energetic parameters for clouding in 1.0 weight percent of hydroxypropylmethyl cellulose (HPMC) solutions in the presence of various salts. The uncertainties in the CP values lie within \pm 0.1 degree.

\begin{tabular}{|c|c|c|c|c|c|c|c|c|c|}
\hline $10^{4} X_{\mathrm{NORT}}$ & $\begin{array}{c}\mathrm{CP} \\
\mathrm{K}\end{array}$ & $\begin{array}{l}\Delta G_{c}{ }^{0} \\
\mathrm{~kJ} / \mathrm{mol} \\
\text { NORT }\end{array}$ & $\begin{array}{c}\Delta H_{c}{ }^{0} \\
\mathrm{~kJ} / \mathrm{mol}\end{array}$ & $\begin{array}{l}T \Delta S_{c}{ }^{0} \\
\mathrm{~kJ} / \mathrm{mol}\end{array}$ & $10^{4} X_{\mathrm{IBF}}$ & $\begin{array}{c}\mathrm{CP} \\
\mathrm{K}\end{array}$ & $\begin{array}{c}\Delta G_{c}{ }^{0} \\
\mathrm{~kJ} \cdot \mathrm{mol} \\
\mathrm{IBF}\end{array}$ & $\begin{array}{c}\Delta H_{c}^{0} \\
\mathrm{~kJ} \cdot \mathrm{mol}\end{array}$ & $\begin{array}{l}T \Delta S_{c}{ }^{0} \\
\mathrm{~kJ} \cdot \mathrm{mol}\end{array}$ \\
\hline \multicolumn{10}{|c|}{ Pure water } \\
\hline 1.16 & 336.15 & -25.31 & -195.49 & -170.17 & 2.91 & 334.15 & -22.62 & -70.16 & -47.54 \\
\hline 2.25 & 337.15 & -23.54 & & -171.95 & 5.63 & 335.15 & -20.85 & & -49.32 \\
\hline 3.28 & 338.15 & -22.55 & & -172.93 & 10.60 & 336.15 & -19.14 & & -51.03 \\
\hline 5.15 & 339.15 & -21.34 & & -174.14 & 20.79 & 338.15 & -17.36 & & -52.81 \\
\hline 6.82 & 340.15 & -20.61 & & -174.87 & 28.67 & 341.15 & -16.61 & & -53.56 \\
\hline 10.30 & 342.15 & -19.56 & & -175.92 & 34.93 & 351.15 & -16.52 & & -53.65 \\
\hline 13.03 & 344.15 & -19.01 & & -176.48 & 37.10 & 355.15 & -16.53 & & -53.64 \\
\hline 15.24 & 346.15 & -18.66 & & -176.82 & 39.10 & 359.15 & -16.56 & & -53.61 \\
\hline 18.60 & 349.15 & -18.25 & & -177.24 & 40.10 & 363.15 & -16.6 & & -53.57 \\
\hline 21.02 & 352.15 & -18.05 & & -177.44 & & & & & \\
\hline \multicolumn{10}{|c|}{$10 \mathrm{mM} \mathrm{NaCl}$} \\
\hline 1.16 & 336.15 & -25.32 & -171.51 & -146.19 & 2.91 & 336.15 & -22.76 & 121.82 & -99.06 \\
\hline 2.25 & 338.15 & -23.61 & & -147.90 & 5.63 & 337.15 & -20.97 & & -100.85 \\
\hline 4.24 & 340.15 & -21.96 & & -149.55 & 10.60 & 338.15 & -19.26 & & -102.57 \\
\hline 6.01 & 342.15 & -21.10 & & -150.42 & 15.02 & 339.15 & -18.33 & & -103.49 \\
\hline 9.67 & 344.15 & -19.86 & & -151.65 & 18.97 & 340.15 & -17.73 & & -104.10 \\
\hline 12.53 & 345.15 & -19.17 & & -152.34 & 27.24 & 342.15 & -16.80 & & -105.02 \\
\hline 16.73 & 348.15 & -18.50 & & -153.01 & 33.78 & 346.15 & -16.38 & & -105.45 \\
\hline 19.66 & 350.15 & -18.14 & & -153.37 & 39.10 & 354.15 & -16.32 & & -105.50 \\
\hline 21.81 & 353.15 & -17.99 & & -153.52 & & & & & \\
\hline \multicolumn{10}{|c|}{$100 \mathrm{mM} \mathrm{NaCl}$} \\
\hline 1.16 & 330.15 & -24.87 & 109.28 & 134.15 & 2.91 & 331.15 & -22.42 & 210.20 & 232.628 \\
\hline 2.25 & 327.15 & -22.84 & & 132.13 & 5.63 & 329.15 & -20.48 & & 230.682 \\
\hline 3.28 & 324.15 & -21.62 & & 130.91 & 10.60 & 327.15 & -18.63 & & 228.837 \\
\hline 4.24 & 321.15 & -20.74 & & 130.02 & 15.02 & 325.15 & -17.57 & & 227.782 \\
\hline 5.15 & 319.15 & -20.09 & & 129.38 & 18.97 & 323.15 & -16.84 & & 227.046 \\
\hline 6.01 & 318.15 & -19.62 & & 128.91 & 22.52 & 324.15 & -16.43 & -19.93 & -3.5059 \\
\hline 6.82 & 317.15 & -19.22 & & 128.51 & 25.74 & 327.15 & -16.22 & & -3.717 \\
\hline 10.30 & 321.15 & -18.37 & -72.74 & -54.38 & 32.59 & 338.15 & -16.1 & & -3.8347 \\
\hline 13.03 & 323.15 & -17.85 & & -54.9 & 38.12 & 348.15 & -16.12 & & -3.8123 \\
\hline 15.25 & 325.15 & -17.53 & & -55.21 & & & & & \\
\hline 17.07 & 327.15 & -17.33 & & -55.41 & & & & & \\
\hline 19.90 & 330.15 & -17.07 & & -55.68 & & & & & \\
\hline \multicolumn{10}{|c|}{$200 \mathrm{mM} \mathrm{NaCl}$} \\
\hline 1.16 & 326.15 & -24.57 & 114.86 & 139.43 & 2.91 & 329.15 & -22.29 & 163.87 & 186.157 \\
\hline 2.25 & 322.15 & -22.49 & & 137.35 & 8.19 & 326.15 & -19.27 & & 183.145 \\
\hline 3.28 & 319.15 & -21.29 & & 136.15 & 12.87 & 324.15 & -17.94 & & 181.808 \\
\hline 5.15 & 315.15 & -19.84 & & 134.7 & 17.04 & 321.15 & -17.02 & & 180.892 \\
\hline 6.82 & 316.15 & -19.16 & 71.64 & -52.47 & 20.79 & 319.15 & -16.39 & & 180.259 \\
\hline 8.32 & 318.15 & -18.76 & & -52.88 & 24.17 & 321.15 & -16.09 & 19.13 & -3.0444 \\
\hline 11.47 & 321.15 & -18.08 & & -53.56 & 27.24 & 323.15 & -15.87 & & -3.2651 \\
\hline 13.97 & 324.15 & -17.71 & & -53.92 & 33.78 & 333.15 & -15.76 & & -3.3708 \\
\hline 16.02 & 327.15 & -17.51 & & -54.13 & 39.10 & 343.15 & -15.82 & & -3.3143 \\
\hline 19.14 & 329.15 & -17.13 & & -54.51 & & & & & \\
\hline 21.43 & 331.15 & -16.92 & & -54.72 & & & & & \\
\hline
\end{tabular}


drugs and polymer was the ionic-dipole interaction between the head group and dipole of the drug and polymer, respectively.

\section{Conflict of Interests}

The authors do not have any conflict of interests regarding this research work.

\section{Acknowledgment}

The authors extend their appreciation to the Deanship of Scientific Research at King Saud University for funding the work through the research group Project no. RGP-VPP-148.

\section{References}

[1] J. F. Kennedy, T. P. Nevell, and S. H. Zeronian, Cellulose and Its Derivatives: Chemistry, Biochemistry and Applications, Ellis Horwood, Oakland, Calif, USA, 1985.

[2] J. Siepmann and N. A. Peppas, "Modeling of drug release from delivery systems based on hydroxypropyl methylcellulose (HPMC)," Advanced Drug Delivery Reviews, vol. 48, no. 2-3, pp. 139-157, 2001.

[3] A. T. Florence and D. Attwood, Physicochemical Principles of Pharmacy, Macmillan, London, UK, 3rd edition, 1998.

[4] G. K. J. Greminger and K. L. Krumel, "Alkyl and hydroxyalkylcellulose," in Handbook of Water-Soluble Gums and Resins, R. L. Davidson, Ed., McGraw-Hill, New York, NY, USA, 1980.

[5] F. Joabsson, O. Rosén, K. Thuresson, L. Piculell, and B. Lindman, "Phase behavior of a "clouding" nonionic polymer in water. Effects of hydrophobic modification and added surfactant on phase compositions," The Journal of Physical Chemistry B, vol. 102, no. 16, pp. 2954-2959, 1998.

[6] X. Wang, J. Wang, Y. Wang, and H. Yan, "Salt effect on the complex formation between cationic gemini surfactant and anionic polyelectrolyte in aqueous solution," Langmuir, vol. 20, no. 21, pp. 9014-9018, 2004.

[7] A. D. Bó, B. Schweitzer, A. C. Felippe, D. Zanette, and B. Lindman, "Ethyl(hydroxyethyl)cellulose-sodium dodecanoate interaction investigated by surface tension and electrical conductivity techniques," Colloids and Surfaces A: Physicochemical and Engineering Aspects, vol. 256, no. 2-3, pp. 171-180, 2005.

[8] M. Olsson, G. Boström, L. Karlson, and L. Piculell, "Added surfactant can change the phase behavior of aqueous polymerparticle mixtures," Langmuir, vol. 21, no. 7, pp. 2743-2749, 2005.

[9] K. Holmberg, B. Jonsson, B. Kronberg, and B. Lindman, Surfactants and Polymers in Aqueous Solutions, John Wiley \& Sons, West Sussex, UK, 2nd edition, 2003.

[10] N. Sardar, M. S. Ali, M. Kamil, and Kabir-ud-Din, "Phase behavior of nonionic polymer hydroxypropylmethyl cellulose: effect of gemini and single-chain surfactants on the energetics at the cloud point," Journal of Chemical \& Engineering Data, vol. 55, no. 11, pp. 4990-4994, 2010.

[11] N. Sardar, M. Kamil, Kabir-ud-Din, and M. S. Ali, "Solution behavior of nonionic polymer hydroxypropylmethyl cellulose: effect of salts on the energetics at the cloud point," Journal of Chemical \& Engineering Data, vol. 56, no. 4, pp. 984-987, 2011.

[12] E. D. Goddard and K. P. Ananthapadmanabhan, Interactions of Surfactants with Polymers and Proteins, CRC Press, Boca Raton, Fla, USA, 1993.
[13] J. C. T. Kwak, Polymer-Surfactant Systems, vol. 77 of Surfactant Science Series, Marcel Dekker, New York, NY, USA, 1998.

[14] M. S. Ali, M. Suhail, G. Ghosh, M. Kamil, and Kabir-ud-Din, "Interactions between cationic gemini/conventional surfactants with polyvinylpyrrolidone: specific conductivity and dynamic light scattering studies," Colloids and Surfaces A: Physicochemical and Engineering Aspects, vol. 350, no. 1-3, pp. 51-56, 2009.

[15] S. Schreier, S. V. P. Malheiros, and E. de Paula, "Surface active drugs: self-association and interaction with membranes and surfactants. Physicochemical and biological aspects," Biochimica et Biophysica Acta-Biomembranes, vol. 1508, no. 1-2, pp. 210-234, 2000.

[16] M. S. Ali and H. A. Al-Lohedan, "Interaction of biocompatible polymers with amphiphilic phenothiazine drug chlorpromazine hydrochloride," Journal of Molecular Liquids, vol. 177, pp. 283-287, 2013.

[17] M. S. Ali, M. A. Rub, F. Khan, H. A. Al-Lohedan, and Kabir-udDin, "Interaction of amphiphilic drug amitriptyline hydrochloride with $\beta$-cyclodextrin as studied by conductometry, surface tensiometry and viscometry," Journal of Molecular Liquids, vol. 167, pp. 115-118, 2012.

[18] M. S. Ali, M. A. Rub, F. Khan, H. A. Al-Lohedan, and Kabirud-Din, " $\beta$-cyclodextrin-promazine hydrochloride interaction: conductometric and viscometric studies," Journal of Saudi Chemical Society, 2012.

[19] M. S. Ali, G. Ghosh, and Kabir-ud-Din, "Amphiphilic drug persuaded collapse of polyvinylpyrrolidone and poly(ethylene glycol) chains: a dynamic light scattering study," Colloids and Surfaces B: Biointerfaces, vol. 75, no. 2, pp. 590-594, 2010.

[20] I. A. Khan, K. Anjum, M. S. Ali, and Kabir-ud-Din, "A comparative study of interaction of ibuprofen with biocompatible polymers," Colloids and Surfaces B: Biointerfaces, vol. 88, no. 1, pp. 72-77, 2011.

[21] I. F. Uchegbu and A. G. Schatzlein, Polymers in Drug Delivery, Pharmacology and Toxicology, CRC Press, Boca Raton, Fla, USA, 2006.

[22] D. Jones, Pharmaceutical Applications of Polymers for Drug Delivery, iSmithers Rapra, Shropshire, UK, 2004.

[23] F. Puoci, G. Cirillo, M. Curcio, O. I. Parisi, F. Iemma, and N. Picci, "Molecularly imprinted polymers in drug delivery: state of art and future perspectives," Expert Opinion on Drug Delivery, vol. 8, no. 10, pp. 1379-1393, 2011.

[24] Medicines Complete, "Pharmaceutical Excipients. Monographs. Sodium chloride," http://www.medicinescomplete. $\mathrm{com} /$.

[25] A. Avdeef, S. Bendels, O. Tsinman, K. Tsinman, and M. Kansy, "Solubility-excipient classification gradient maps," Pharmaceutical Research, vol. 24, no. 3, pp. 530-545, 2007.

[26] P. M. S. Allaudin and J. Kunchthapatham, "A review of on performulation studies of drugs," International Journal of Pharmaceutical Research and Development, vol. 4, no. 6, pp. 64-74, 2012.

[27] V. G. Gaikar and V. Latha, "Hydrotropic properties of sodium salt of ibuprofen," Drug Development and Industrial Pharmacy, vol. 23, no. 3, pp. 309-312, 1997.

[28] G. Karlstroem, "A new model for upper and lower critical solution temperatures in poly(ethylene oxide) solutions," The Journal of Physical Chemistry, vol. 89, no. 23, pp. 4962-4964, 1985.

[29] A. Carlsson, G. Karlstrom, and B. Lindman, "Synergistic surfactant-electrolyte effect in polymer solutions," Langmuir, vol. 2, no. 4, pp. 536-537, 1986. 
[30] R. Nagarajan, "Micellization, mixed micellization and solubilization: the role of interfacial interactions," Advances in Colloid and Interface Science, vol. 26, pp. 205-264, 1986.

[31] M. J. Rosen, Surfactants and Interfacial Phenomena, WileyInterscience, Hoboken, NJ, USA, 3rd edition, 2004.

[32] D. Myers, Surfactant Science and Technology, Wiley-Interscience, Hoboken, NJ, USA, 3rd edition, 2006.

[33] K. Holmberg, B. Jönsson, B. Kronberg, and B. Lindman, Surfactants and Polymers in Aqueous Solution, John Wiley \& Sons, West Sussex, UK, 2nd edition, 2002.

[34] M. Malmsten and B. Lindman, "Ellipsometry studies of the adsorption of cellulose ethers," Langmuir, vol. 6, no. 2, pp. 357364, 1990.

[35] G. Karlstrom, A. Carlsson, and B. Lindman, "Phase diagrams of nonionic polymer-water systems: experimental and theoretical studies of the effects of surfactants and other cosolutes," The Journal of Physical Chemistry, vol. 94, no. 12, pp. 5005-5015, 1990.

[36] A. Dan, S. Ghosh, and S. P. Moulik, "The solution behavior of poly(vinylpyrrolidone): its clouding in salt solution, solvation by water and isopropanol, and interaction with sodium dodecyl sulfate," The Journal of Physical Chemistry B, vol. 112, no. 12, pp. 3617-3624, 2008.

[37] Kabir-ud-Din, A. Z. Naqvi, A. B. Khan, M. D. A. Al-Ahmadi, and M. Akram, "Energetics of drug-additive systems at the cloud point," Journal of Chemical \& Engineering Data, vol. 54, no. 2, pp. 387-391, 2009. 

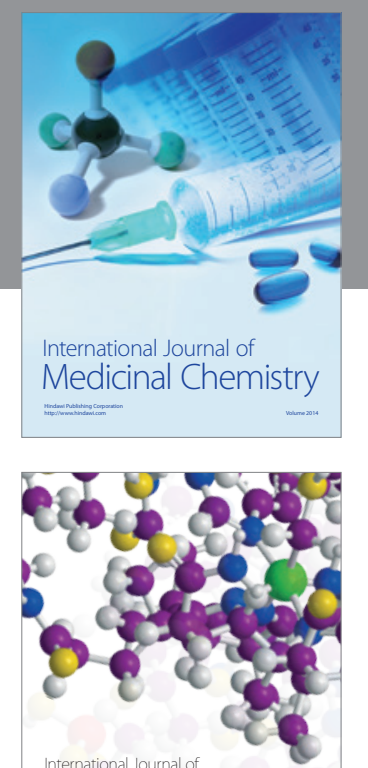

\section{Carbohydrate} Chemistry

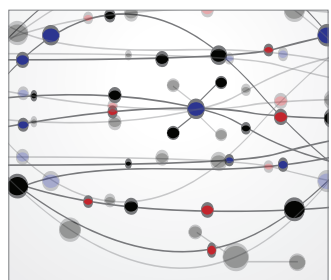

The Scientific World Journal
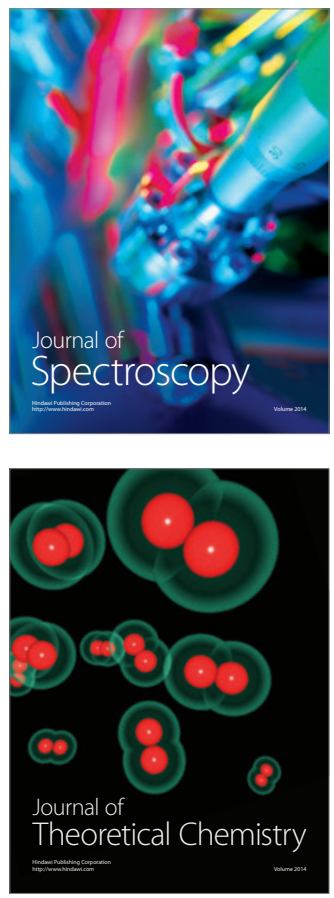
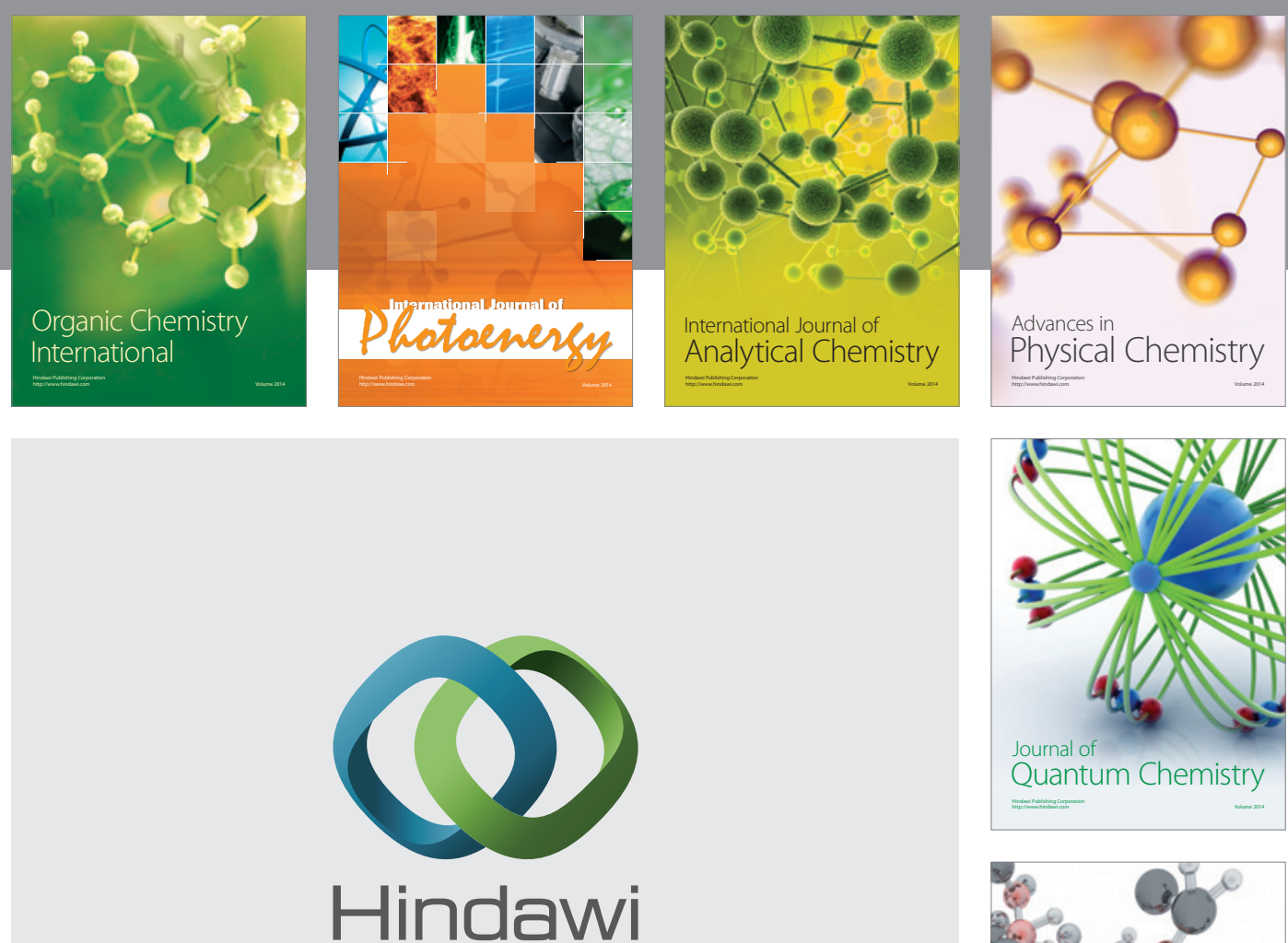

Submit your manuscripts at

http://www.hindawi.com

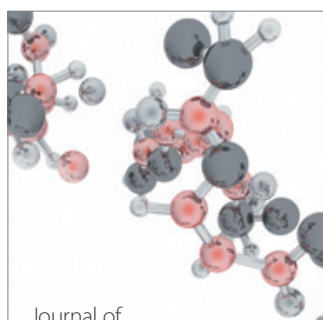

Analytical Methods

in Chemistry

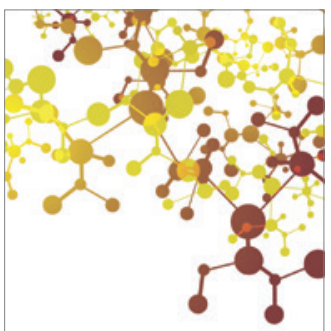

Journal of

Applied Chemistry

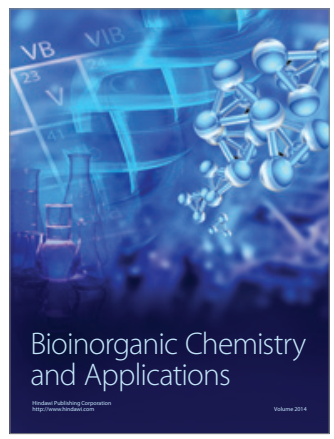

Inorganic Chemistry
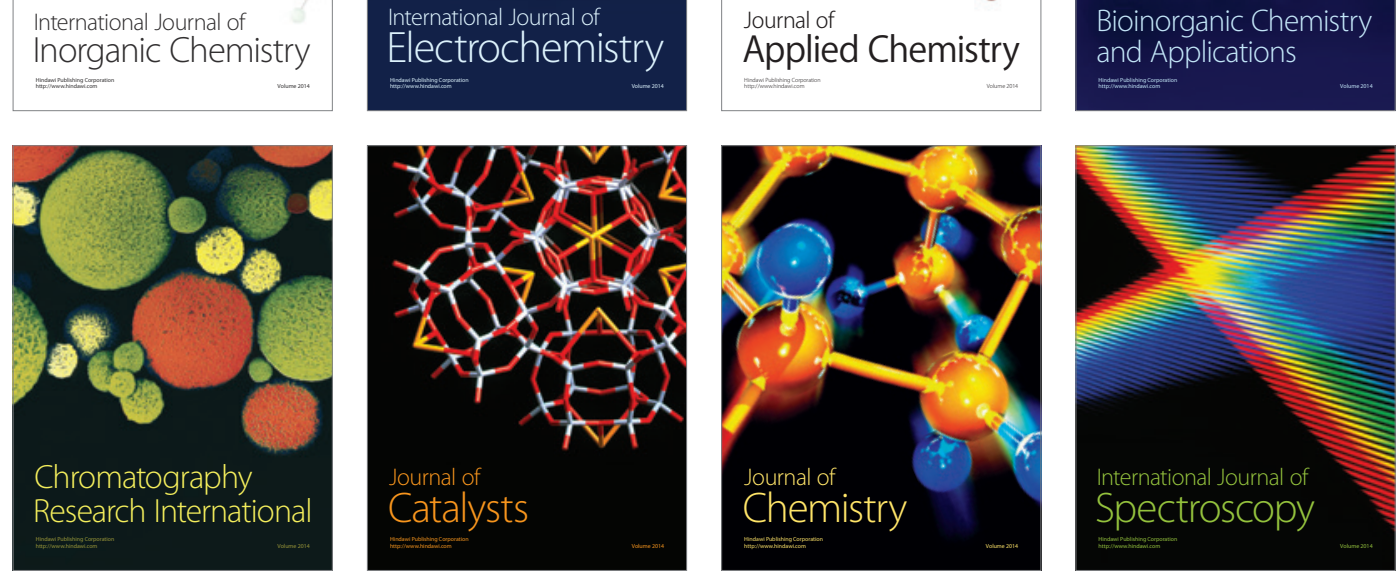